\title{
Characterization of the residues in Han Dynasty bronze lamps by pyrolysis-gas chromatography-mass spectrometry
}

\author{
Huarui Han ${ }^{1}$, Shuya Wei ${ }^{*}$, Jun Yang ${ }^{2}$, Li Guan ${ }^{2}$ and Wenhuan Li
}

\begin{abstract}
The fuel residues in two bronze lamps excavated from Haihunhou Tomb in the Han Dynasty, in Jiangxi Province, China, were studied in this paper. The techniques of Fourier transform infrared (FT-IR) spectroscopy and pyrolysis-gas chromatography-mass spectrometry with thermal-assisted hydrolysis and methylation (THM-Py-GC/MS) were used to characterize the materials. Long-chain fatty acids, fatty alcohols and hydrocarbons were detected as the main components. By comparing the reference materials of beeswax and Chinese wax, the residues in the lamps were identified as beeswax. Furthermore, according to the morphology of the remains of the lamp fuel, the fuel remains were probably melted and then solidified, which suggests the lamps were used. Wax was found to have been used as an illuminating fuel as early as the Han Dynasty, enriching scholarly knowledge about the lighting materials used in ancient China.
\end{abstract}

Keywords: Py-GC/MS, Beeswax, Chinese wax, Illuminating fuel, Haihunhou Tomb

\section{Introduction}

Haihunhou Tomb (Western Han Dynasty, 202BC-AD8) was discovered in 2015 and is located south of Poyang Lake, Nanchang city, Jiangxi Province, China (Fig. 1). Liuhe was the emperor of the Western Han for just 27 days before being dethroned (63 B.C.). After being dethroned, he received his new rank of Haihunhou (the rank of nobility in the Han Dynasty) and the lands around Poyang Lake, where he eventually was buried. His coffin was in M1. Surprisingly, massive amounts of burial goods were found in this tomb, including a large pile of bronze coins (approximately 10 tons), a great number of gold and silver wares, bronze, lacquered musical instruments, porcelain goods, and very valuable lacquer paintings $[1,2]$. Among these findings were two bronze lamps, numbered M1:1641 (Gang lamp) and M1:1681 (Yanzu lamp) [3] (Fig. 2). Luckily, remains of the illuminating fuel

\footnotetext{
*Correspondence: Sywei66@hotmail.com

${ }^{1}$ Institute of Cultural Heritage and History of Science \& Technology, University of Science and Technology Beijing, 30 Xueyuan Road, Beijing, China

Full list of author information is available at the end of the article
}

were found inside the lamps, which is particularly rare and provides an opportunity to study the illuminating fuels used in the Han Dynasty. The sampling locations are marked in Fig. 3.

In recent years, there have been some reports about illuminating fuels. The most common kinds of lamp fuel are plant oil $[4,5]$, animal fat $[6,7]$, and wax. However, among these, archaeological examples of wax fuels are not abundant [8]. Moreover, in different areas, different kinds of materials were used as lamp oils. For example, olive oil has been found mostly around the Mediterranean, including in Roman [9] and Egyptian sites [4], because different material resources were available. According to the ancient literatures, in addition to beeswax, Chinese wax was also used in early China, which was recorded in Compendium of Materia Medica (本草纲目) [10]. This material is a white to yellowishwhite gelatinous substance secreted by certain insects, such as Ceroplastes ceriferus and Ericerus pela. The main components in Chinese wax are wax esters formed by monosaturated fatty acids and monosaturated fatty alcohols [11], which are similar to the components in beeswax. The differences of molecular signatures between 


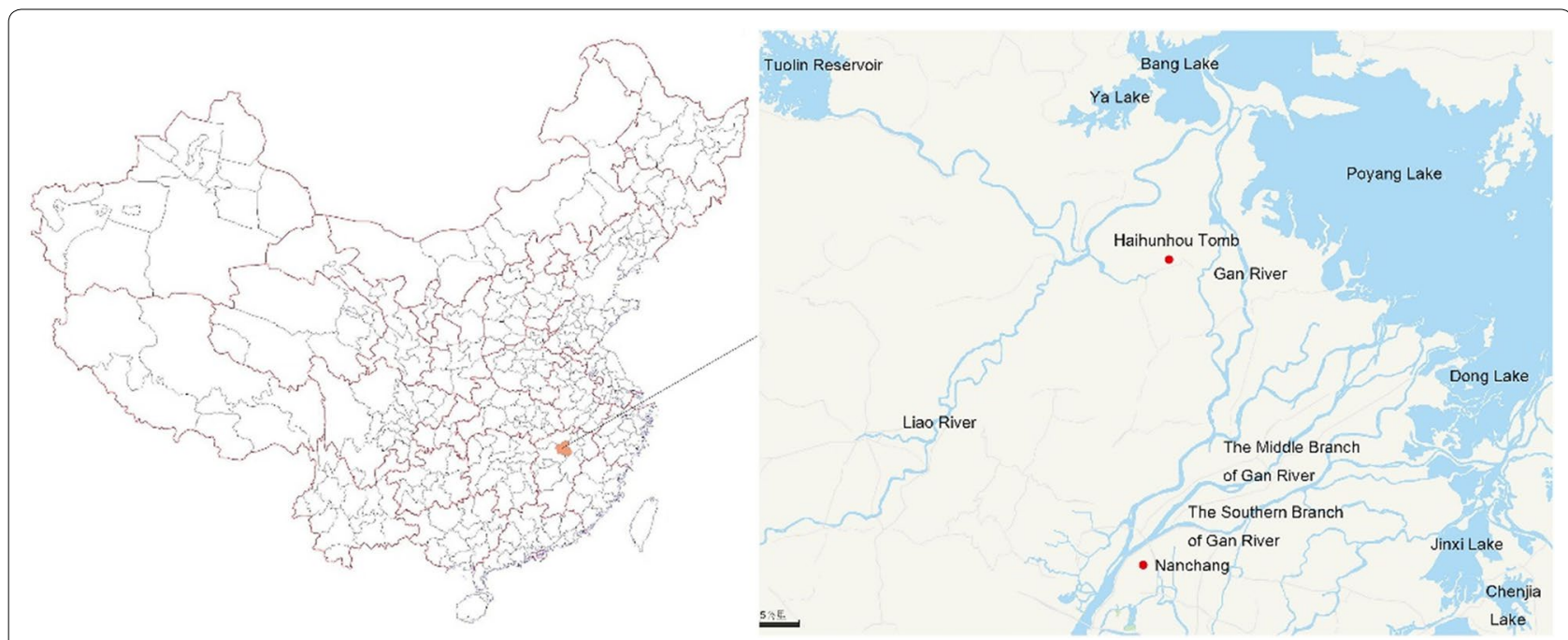

Fig. 1 Location of Haihunhou Tomb
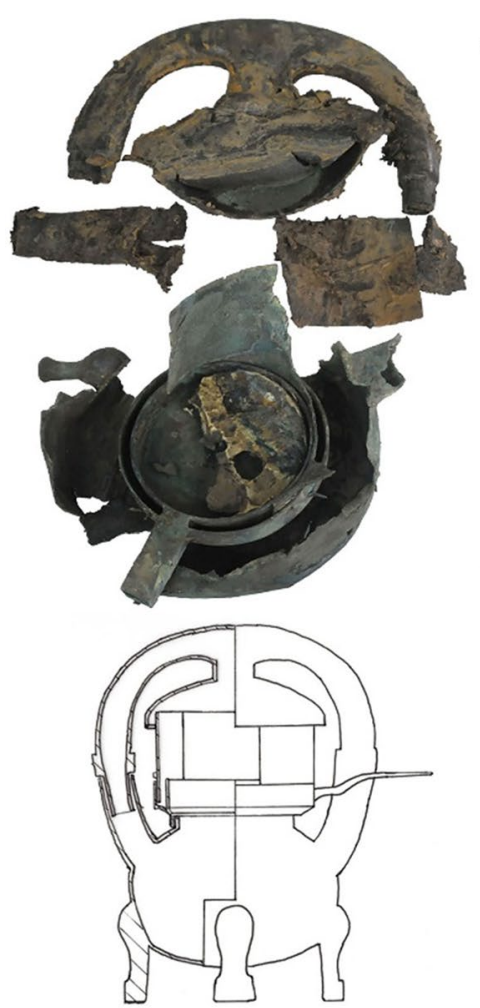

$\mathbf{a}$

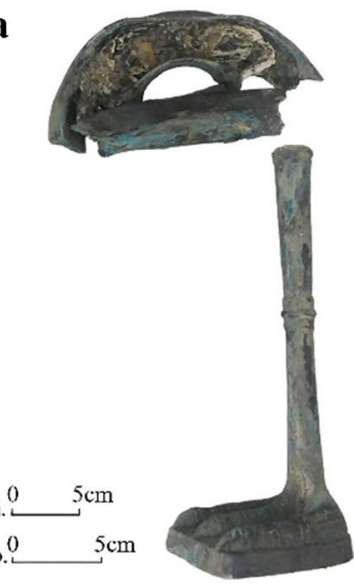

c

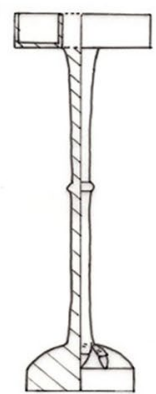

$\mathbf{b}$

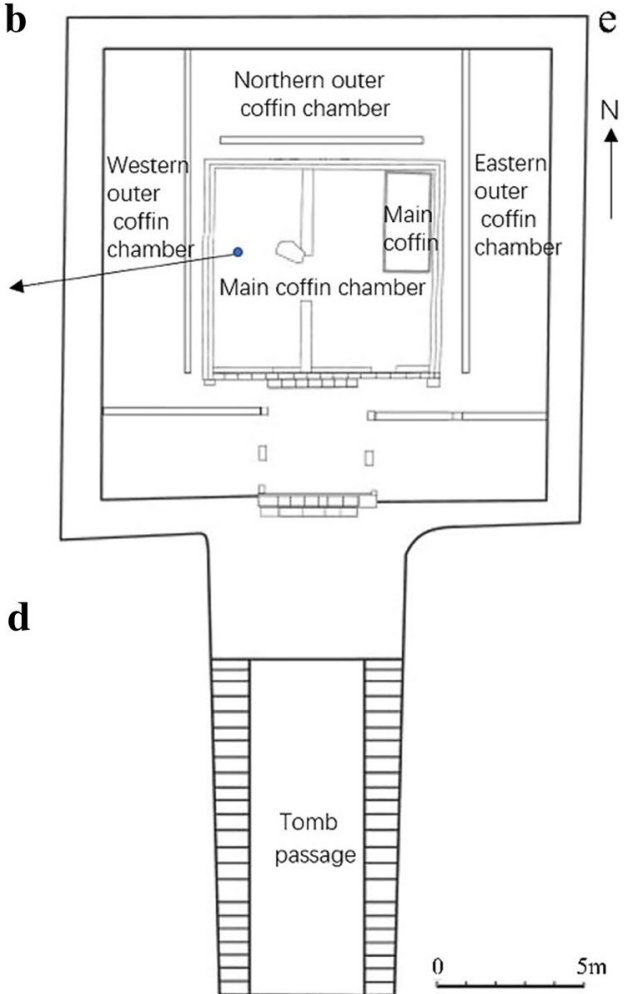

Fig. 2 Excavation of two bronze lamps. a A picture of the bronze lamp numbered M1:1641. b A picture of the bronze lamp numbered M1:1681. c A schematic of M1:1641 after restoration. $\mathbf{d}$ A schematic of M1:1681 after restoration. e The layout of the M1 tomb, and the dot indicates the location from which the two lamps were excavated

these two materials mainly are relative content of the fatty acids and alcohols. Chinese wax has a higher melting point and harder than beeswax.
The main techniques used to characterize organic remains from cultural heritage sites are Fourier transform infrared (FT-IR) spectrometry [12], high-performance liquid chromatography-mass spectrometry (LC/MS) [9], 

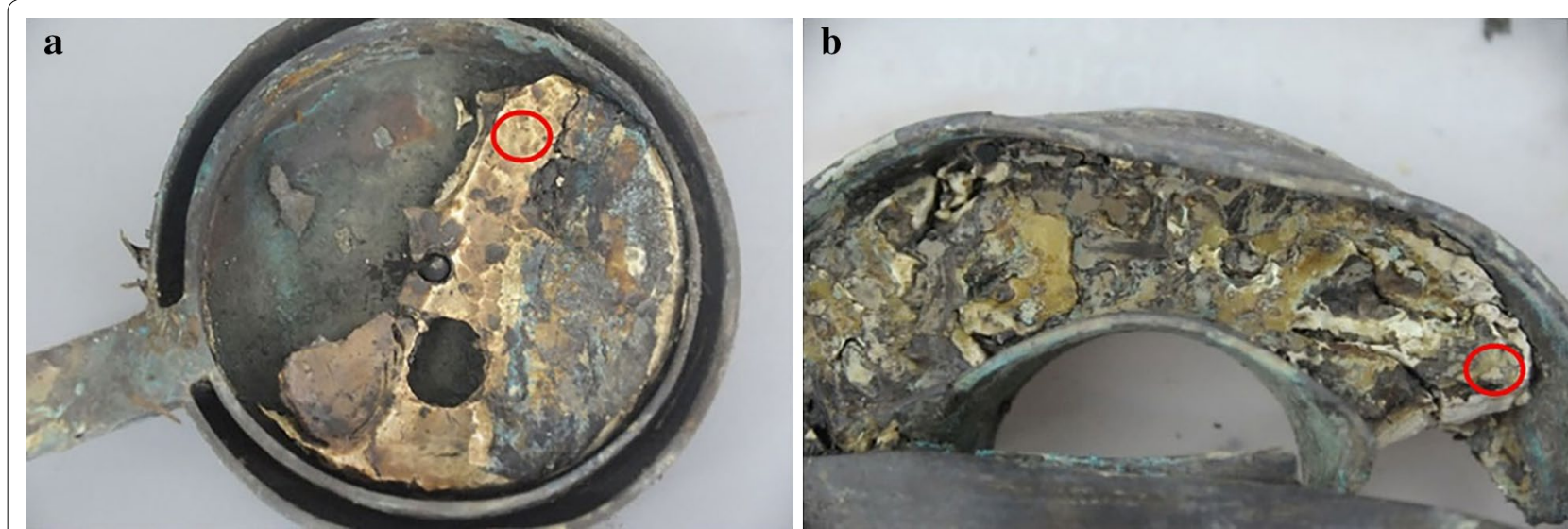

Fig. 3 Locations from which the archaeological samples were taken. a A picture of the M1:1641 lamp panel. b A picture of the M1:1681 lamp panel. The red circles indicate the sampling locations

gas chromatography coupled to mass spectrometry (GC/ MS) [13-17], high-temperature gas chromatography coupled to mass spectrometry (HT-GS) [18] and pyrolysis-gas chromatography-mass spectrometry (Py-GC/ MS) [19-22]. Py-GC/MS with thermally-assisted hydrolysis and methylation (THM) has the advantages of offering high sensitivity and requiring a facile pretreatment of the samples [23], and this method has been successfully used to characterize the remains in Tang Dynasty lamps [20]. Thus, THM-Py-GC/MS in conjunction with FT-IR spectrometry was chosen for this study. The results provide evidence for the materials used by the aristocracy of the Han Dynasty to illuminate dark spaces.

\section{Experimental}

\section{Samples}

The two canary-yellowish samples were taken from the bronze Gang lamp numbered M1:1641 and the bronze
Yanzu lamp numbered M1:1681, which were found in the western chamber of Haihunhou Tomb (Fig. 3). Reference samples were Chinese wax, purchased from Emeishan in Sichuan Province and beeswax, bought from apiarist in Shanxi Province. Another name of Chinese wax is Sichuan wax, because it was original produced in Sichuan Province. These reference samples can represent the kinds of wax typically used in ancient China.

\section{Fourier transform infrared (FT-IR) spectrometry}

The FT-IR analyses were carried out on a Nicolet 6700 advanced Fourier transform infrared spectrometer (American ThermoFisher Scientific Cooperation). The spectra were collected over the $4000-500 \mathrm{~cm}^{-1}$ region using attenuated total reflectance (ATR) for the measurements.

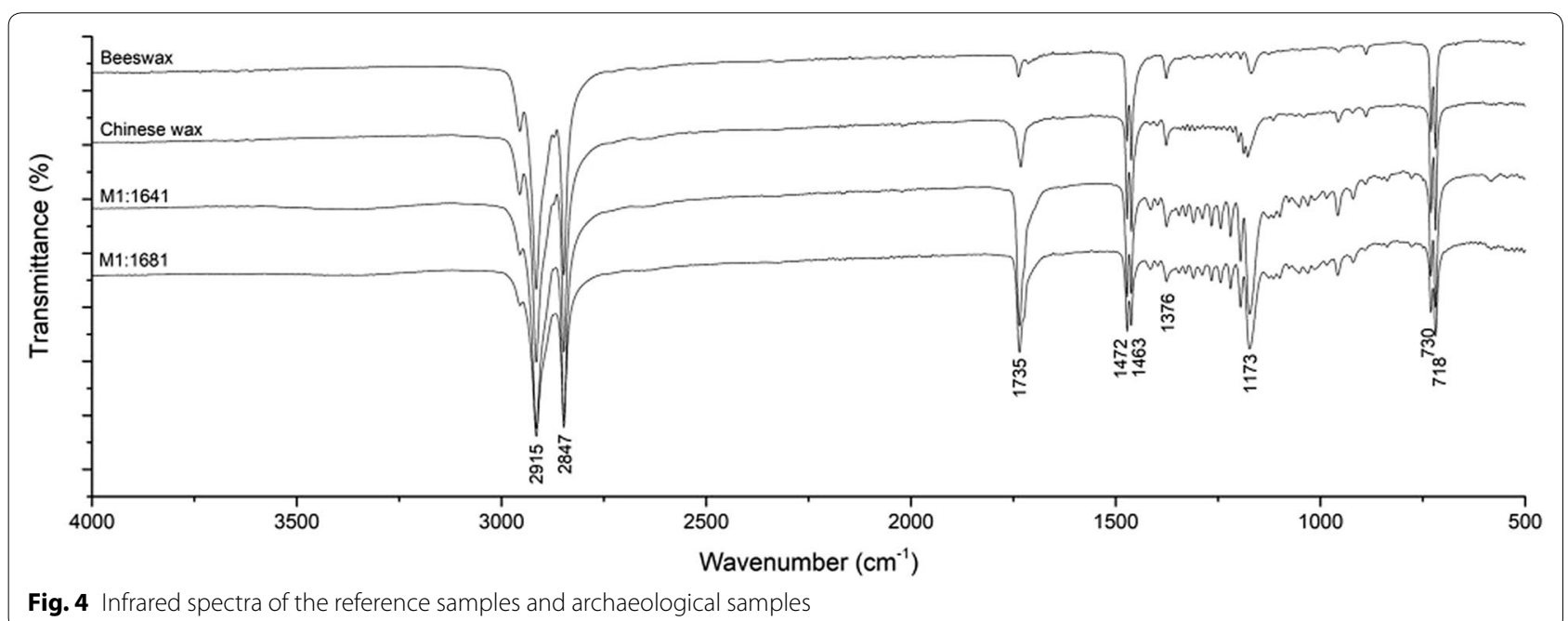




\section{Pyrolysis-gas chromatography-mass spectrometry (Py-} $\mathrm{GC} / \mathrm{MS}$ )

The Py-GC/MS analyses were carried out on a pyrolyzer EGA/PY-3030D (Frontier Lab, Japan) attached to a GCMS QP2010Ultra instrument (Shimadzu, Japan). The pyrolyzer furnace temperature was set at $550^{\circ} \mathrm{C}$, and the injector was set at $300{ }^{\circ} \mathrm{C}$. The samples were held in the furnace for $6 \mathrm{~s}$ to achieve pyrolyzation completely. The initial chromatographic temperature was $50{ }^{\circ} \mathrm{C}$, and the temperature was increased at $10{ }^{\circ} \mathrm{C} / \mathrm{min}$ to $320{ }^{\circ} \mathrm{C}$ and then held for $20 \mathrm{~min}$. The carrier gas was helium, and the split ratio was 1:100. The electron ionization voltage of the mass spectrometer was $70 \mathrm{eV}$. The temperatures of the interface and the ion source were $280{ }^{\circ} \mathrm{C}$ and $200{ }^{\circ} \mathrm{C}$, respectively. The mass data was collected from $\mathrm{m} / \mathrm{z} 30$ to 750 with a scan time of $0.5 \mathrm{~s}$.
Approximately $0.2 \mathrm{mg}$ of the sample was placed in a sample cup, and $3 \mu \mathrm{l}$ of $25 \%$ aqueous TMAH (tetramethyl ammonium hydroxide, analytically pure, Sinopharm Chemical Reagent Co., Ltd.) was added. The TMAH converted the fatty acids and alcohols into homologous methyl esters and methyl ethers, respectively. The NIST14 Library and NIST14 s Library were used to identify the compounds. The normalized areas were used to evaluate the peaks.

\section{Results and discussion}

FT-IR analysis results

The results of FT-IR analysis are shown in Fig. 4, and all the samples, including both the archaeological samples and the reference samples, exhibited similar spectra. The major infrared transmittance peaks appear at

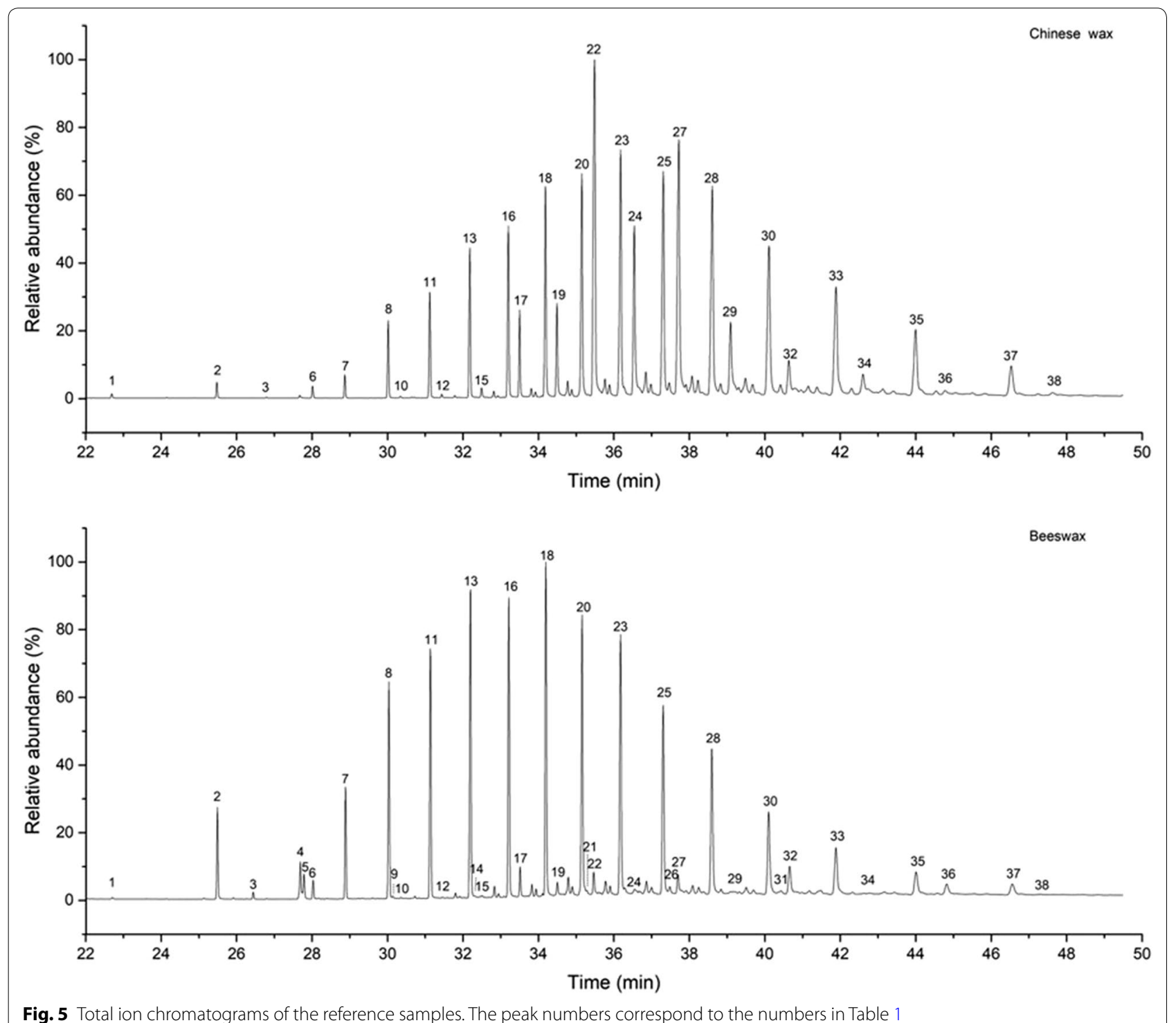

Fig. 5 Total ion chromatograms of the reference samples. The peak numbers correspond to the numbers in Table 1 
wavenumbers $\left(\mathrm{cm}^{-1}\right) 2915,2847,1735,1463,1376,1173$, 730 , and 718. Among these, the bands at $2847 \mathrm{~cm}^{-1}$ and $2915 \mathrm{~cm}^{-1}$ are associated with $-\mathrm{CH}_{2}-$ stretching vibrations, indicating the presence of long-chain alkyl groups; the band at $1462 \mathrm{~cm}^{-1}$ represents bending vibrations of $\mathrm{CH}_{2}-$; the bands at $718 \mathrm{~cm}^{-1}$ and $730 \mathrm{~cm}^{-1}$ are from planar rocking vibrations of $-\mathrm{CH}_{2}-$, and the appearance of two peaks indicates that there are crystallized compounds with long-chain alkyl groups; the band at $1735 \mathrm{~cm}^{-1}$ is from the stretching vibrations of the carboxyl groups of esters; the bands at $1173 \mathrm{~cm}^{-1}$ and $1130 \mathrm{~cm}^{-1}$ are from the stretching vibrations of $\mathrm{C}-\mathrm{O}-\mathrm{C}$ moieties, confirming the presence of esters. All the samples showed similar absorption peaks ranging from 1376 to $1195 \mathrm{~cm}^{-1}$, and these bands can be attributed to out-of-plane vibrations of $-\mathrm{CH}_{2}-$ in long-chain aliphatic groups. In addition,

Table 1 Compounds identified in the chromatograms of the reference samples

\begin{tabular}{|c|c|c|c|c|c|}
\hline \multirow[t]{2}{*}{ Peak number } & \multirow[t]{2}{*}{ Ret. time (min) } & \multirow[t]{2}{*}{ Identified compound } & \multirow{2}{*}{$\begin{array}{l}\text { Original } \\
\text { molecular formula }\end{array}$} & \multicolumn{2}{|c|}{ Peak area (\%) Mean \pm SD } \\
\hline & & & & Chinese wax & Beeswax \\
\hline 1 & 22.70 & Tetradecanoic acid methyl ester & $\mathrm{C}_{14} \mathrm{H}_{28} \mathrm{O}_{2}$ & $0.30 \pm 0.16$ & $0.05 \pm 0.02$ \\
\hline 2 & 25.49 & Hexadecanoic acid methyl ester & $\mathrm{C}_{16} \mathrm{H}_{32} \mathrm{O}_{2}$ & $0.78 \pm 0.39$ & $2.67 \pm 0.72$ \\
\hline 3 & 26.44 & Heneicosane & $\mathrm{C}_{21} \mathrm{H}_{44}$ & $0.03 \pm 0.03$ & $0.13 \pm 0.04$ \\
\hline 4 & 27.69 & 9-Octadecenoic acid methyl ester & $\mathrm{C}_{18} \mathrm{H}_{34} \mathrm{O}_{2}$ & & $0.57 \pm 0.29$ \\
\hline 5 & 27.78 & 15-Methoxyhexadecanoic acid methyl ester & $\mathrm{C}_{16} \mathrm{H}_{32} \mathrm{O}_{3}$ & & $0.29 \pm 0.12$ \\
\hline 6 & 28.02 & Octadecanoic acid methyl ester & $\mathrm{C}_{18} \mathrm{H}_{36} \mathrm{O}_{2}$ & $0.27 \pm 0.13$ & $0.67 \pm 0.19$ \\
\hline 7 & 28.88 & Docosane & $\mathrm{C}_{22} \mathrm{H}_{46}$ & $0.65 \pm 0.07$ & $2.56 \pm 0.71$ \\
\hline 8 & 30.03 & Tricosane & $\mathrm{C}_{23} \mathrm{H}_{48}$ & $0.57 \pm 0.15$ & $5.15 \pm 1.42$ \\
\hline 9 & 30.13 & 17-Methoxyoctadecanoic acid methyl ester & $\mathrm{C}_{18} \mathrm{H}_{36} \mathrm{O}_{3}$ & & $0.02 \pm 0.01$ \\
\hline 10 & 30.35 & Eicosanoic acid methyl ester & $\mathrm{C}_{20} \mathrm{H}_{40} \mathrm{O}_{2}$ & $0.06 \pm 0.02$ & $0.02 \pm 0.01$ \\
\hline 11 & 31.13 & Tetracosane & $\mathrm{C}_{24} \mathrm{H}_{50}$ & $2.09 \pm 0.46$ & $6.95 \pm 1.38$ \\
\hline 12 & 31.45 & Docosanol methyl ether & $\mathrm{C}_{22} \mathrm{H}_{46} \mathrm{O}$ & $0.05 \pm 0.03$ & $0.01 \pm 0.00$ \\
\hline 13 & 32.19 & Pentacosane & $\mathrm{C}_{25} \mathrm{H}_{52}$ & $3.07 \pm 0.43$ & $9.03 \pm 1.31$ \\
\hline 14 & 32.30 & 19-Methoxyeicosanoic acid methyl ester & $\mathrm{C}_{20} \mathrm{H}_{40} \mathrm{O}_{3}$ & & $0.02 \pm 0.01$ \\
\hline 15 & 32.50 & Docosanoic acid methyl ester & $\mathrm{C}_{22} \mathrm{H}_{44} \mathrm{O}_{2}$ & $0.43 \pm 0.18$ & $0.04 \pm 0.01$ \\
\hline 16 & 33.21 & Hexacosane & $\mathrm{C}_{26} \mathrm{H}_{54}$ & $4.07 \pm 0.48$ & $9.42 \pm 0.70$ \\
\hline 17 & 33.51 & Tetracosanol methyl ether & $\mathrm{C}_{24} \mathrm{H}_{50} \mathrm{O}$ & $1.25 \pm 0.60$ & $0.60 \pm 0.23$ \\
\hline 18 & 34.19 & Heptacosane & $\mathrm{C}_{27} \mathrm{H}_{56}$ & $4.07 \pm 0.54$ & $10.05 \pm 0.48$ \\
\hline 19 & 34.50 & Tetracosanoic acid methyl ester & $\mathrm{C}_{24} \mathrm{H}_{48} \mathrm{O}_{2}$ & $3.66 \pm 0.99$ & $0.33 \pm 0.09$ \\
\hline 20 & 35.15 & Octacosane & $\mathrm{C}_{28} \mathrm{H}_{58}$ & $4.79 \pm 0.58$ & $9.23 \pm 0.42$ \\
\hline 21 & 35.28 & Methoxytetracosanediol methyl ethers & $\mathrm{C}_{24} \mathrm{H}_{50} \mathrm{O}_{2}$ & & $0.02 \pm 0.01$ \\
\hline 22 & 35.46 & Hexacosanol methyl ether & $\mathrm{C}_{26} \mathrm{H}_{54} \mathrm{O}$ & $10.10 \pm 2.20$ & $0.60 \pm 0.14$ \\
\hline 23 & 36.17 & Nonacosane & $\mathrm{C}_{29} \mathrm{H}_{60}$ & $6.41 \pm 0.77$ & $9.26 \pm 0.77$ \\
\hline 24 & 36.55 & Hexacosanoic acid methyl ester & $\mathrm{C}_{26} \mathrm{H}_{52} \mathrm{O}_{2}$ & $8.74 \pm 3.93$ & $0.16 \pm 0.10$ \\
\hline 25 & 37.30 & Triacontane & $\mathrm{C}_{30} \mathrm{H}_{62}$ & $6.83 \pm 0.64$ & $7.41 \pm 0.88$ \\
\hline 26 & 37.48 & Methoxyhexacosanediol methyl ethers & $\mathrm{C}_{26} \mathrm{H}_{54} \mathrm{O}_{2}$ & & $0.19 \pm 0.01$ \\
\hline 27 & 37.69 & Octacosanol methyl ether & $\mathrm{C}_{28} \mathrm{H}_{58} \mathrm{O}$ & $9.56 \pm 0.67$ & $0.50 \pm 0.10$ \\
\hline 28 & 38.59 & Hentriacontane & $\mathrm{C}_{31} \mathrm{H}_{64}$ & $7.89 \pm 0.15$ & $6.78 \pm 0.88$ \\
\hline 29 & 39.09 & Octacosanoic acid methyl ester & $\mathrm{C}_{28} \mathrm{H}_{56} \mathrm{O}_{2}$ & $4.36 \pm 1.61$ & $0.05 \pm 0.02$ \\
\hline 30 & 40.10 & Dotriacontane & $\mathrm{C}_{32} \mathrm{H}_{66}$ & $7.71 \pm 1.42$ & $4.98 \pm 0.72$ \\
\hline 31 & 40.43 & Methoxyoctacosanediol methyl ethers & $\mathrm{C}_{28} \mathrm{H}_{58} \mathrm{O}_{2}$ & & $0.14 \pm 0.01$ \\
\hline 32 & 40.65 & Triacontanol methyl ether & $\mathrm{C}_{30} \mathrm{H}_{62} \mathrm{O}$ & $0.81 \pm 0.40$ & $1.09 \pm 0.29$ \\
\hline 33 & 41.88 & Tritriacontane & $\mathrm{C}_{33} \mathrm{H}_{68}$ & $5.46 \pm 0.64$ & $4.28 \pm 1.02$ \\
\hline 34 & 42.62 & Triacontanoic acid methyl ester & $\mathrm{C}_{30} \mathrm{H}_{60} \mathrm{O}_{2}$ & $1.38 \pm 0.51$ & $0.04 \pm 0.01$ \\
\hline 35 & 44.00 & Tetratriacontane & $\mathrm{C}_{34} \mathrm{H}_{70}$ & $3.13 \pm 0.51$ & $3.15 \pm 1.33$ \\
\hline 36 & 44.81 & Dotriacontanol methyl ether & $\mathrm{C}_{32} \mathrm{H}_{66} \mathrm{O}$ & $0.15 \pm 0.06$ & $0.48 \pm 0.21$ \\
\hline 37 & 46.56 & Pentatriacontane & $\mathrm{C}_{35} \mathrm{H}_{72}$ & $1.51 \pm 0.23$ & $3.04 \pm 1.52$ \\
\hline 38 & 47.67 & Dotriacontanoic acid methyl ester & $\mathrm{C}_{32} \mathrm{H}_{64} \mathrm{O}_{2}$ & $0.33 \pm 0.23$ & $0.01 \pm 0.00$ \\
\hline
\end{tabular}


the band at $3300-3400 \mathrm{~cm}^{-1}$ indicates that alcoholic hydroxyl groups are present in the samples [24]. In conclusion, the main components of the samples are longchain alkyl groups, including long-chain hydrocarbons, esters, fatty acids and alcohols, which indicates that the archaeological samples are wax $[25,26]$.

Although the infrared spectra obtained from the beeswax and Chinese wax were quite similar to those from the archaeological samples, there were small differences in the peaks at $1195-1376 \mathrm{~cm}^{-1}, 1730 \mathrm{~cm}^{-1}$, and $3300-$ $3400 \mathrm{~cm}^{-1}$. The $1730 \mathrm{~cm}^{-1}$ peak of the archaeological residues is more intense than that of the reference samples, indicating that there are more free fatty acids in the archaeological samples. In addition, the peaks at 1195$1376 \mathrm{~cm}^{-1}$ and $3300-3400 \mathrm{~cm}^{-1}$ in the spectra of them are more intense than the corresponding peaks in the spectra of the reference materials, meaning that there are more long-chain aliphatic constituents in the archaeological samples. These differences indicate that some of the wax esters in the residues of bronze lamps degraded during burial [12]. However, classifying the kind of wax was still difficult, so further investigations using other complementary analytical techniques were needed.

\section{Py-GC/MS analysis results}

Following TMAH derivatization, the reference samples of beeswax and Chinese wax were analysed by PyGC/MS. Figure 5 shows the total ion chromatograms, and the identified compounds with their retention times, as well as the peak areas (three parallel analyses were carried out for each sample) are reported in Table 1. Using the THM method, fatty acids and alcohols, including both free and ester-bound compounds, can be converted into the corresponding methyl esters and ethers respectively, and this conversion is highly efficient [21]. In the case of beeswax, long-chain fatty acids, fatty alcohols and hydrocarbons were detected. The fatty acids present including linear monocarboxylic acids (saturated fatty acids ranging from $\mathrm{C} 14$ to $\mathrm{C} 32$, with $\mathrm{C} 16$ being the most abundant, and the unsaturated fatty acid C18:1) and linear $\omega$-1-hydroxy fatty acids (ranging from $\mathrm{C} 16$ to $\mathrm{C} 20$, with the most abundant being 15-hydroxyhexadecanoic acid), and all with carbon atoms of even number. The fatty alcohols present including linear monohydric alcohols (ranging from $\mathrm{C} 22$ to $\mathrm{C} 32$, with the most abundant being C30) and linear $\alpha-(\omega-1)$ diols (ranging from $\mathrm{C} 24$ to $\mathrm{C} 28)$, also with carbon atoms of even number. The hydrocarbons present including linear alkanes (ranging from C21 to C35, with the most abundant being C27) with carbon atoms of both odd and even numbers, and the alkanes with carbons of odd numbers were more abundant than with even-numbered, and minor amounts of alkenes are present. The main chromatographic features of raw beeswax are in accordance with the literature [16, $19,21]$. Moreover, according to the research about fingerprints of beeswax from 10 provinces in China, the components vary slightly on relative amount as their fingerprint characteristics [27], meaning that although the beeswax samples have different origins, the main features are same.

The main fractions of Chinese wax are similar to those of beeswax. Linear monocarboxylic acids with carbons of even numbers ranging from $\mathrm{C} 14$ to C32 were detected, and the most abundant species was C26:0. Linear monohydric alcohols with carbons of
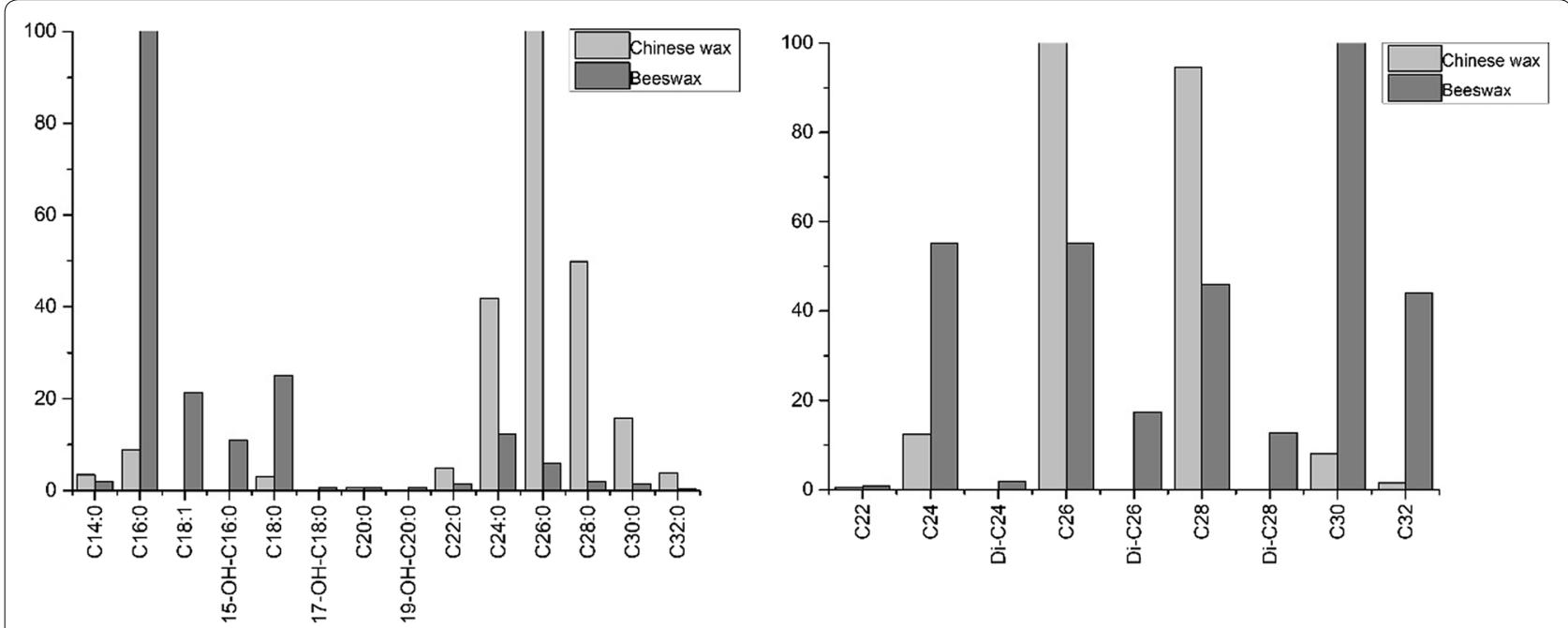

Fig. 6 The relative abundances of fatty acids (left) and alcohols (right) in the reference samples 
even numbers ranging from $\mathrm{C} 22$ to $\mathrm{C} 32$ were also identified, and the most abundant was C26. The observed long-chain hydrocarbons were primarily linear-chain alkanes, and both odd and even numbers of carbons were found. Triacontane and hentriacontane are the dominant species in Chinese wax, and the relative abundance of alkanes increased gradually from C21 to C29 and decreased from C30 to C35.

The main difference between Chinese wax and beeswax is the relative abundance of long-chain fatty acids, fatty alcohols and alkanes. In beeswax, the major compounds are hexadecanoic acid, triacontanol, and heptacosane,

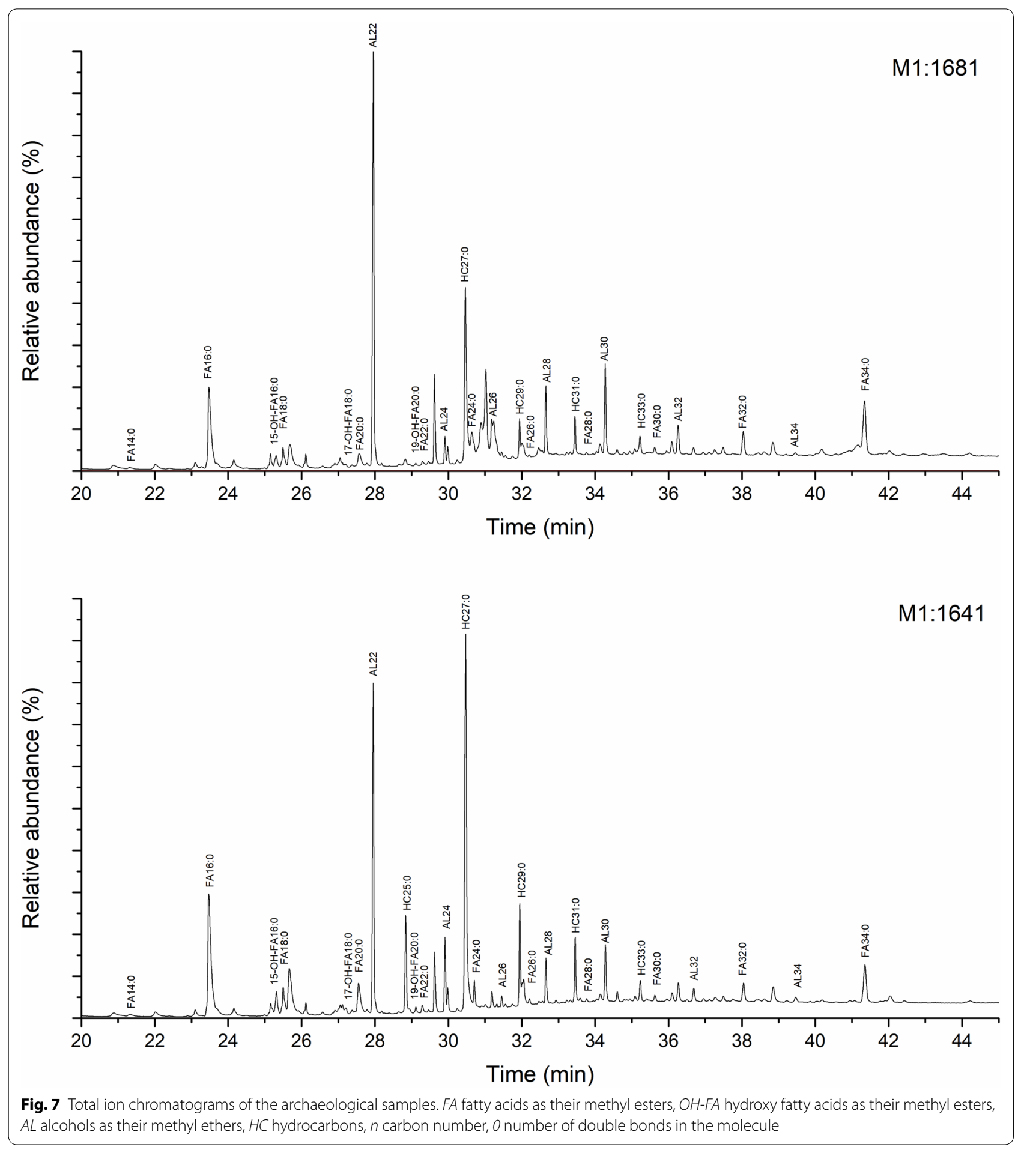




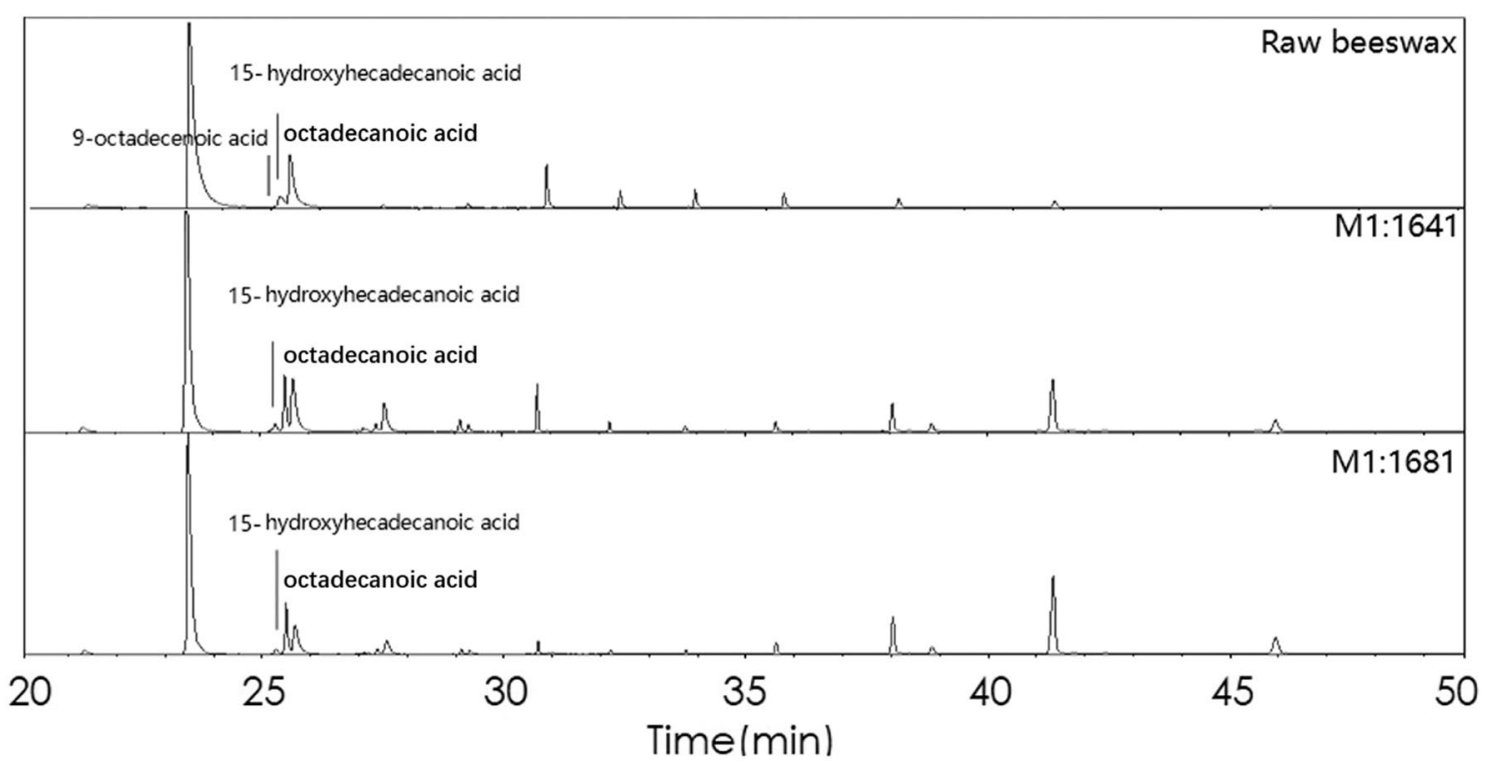

Fig. 8 Extracted ion chromatograms at $m / z 74$

while hexacosanoic acid, hexacosanol, and nonacosane are the dominant species in Chinese wax. In addition, linear $\omega$-1-hydroxy fatty acids, 9-octadecenoic acid (C18:1), and linear $\alpha-(\omega-1)$ diols are only found in beeswax but were not detected in Chinese wax (Fig. 6).

Furthermore, artificial ageing of the reference materials by heating has been performed. Through analysis, no differences between the unaged and aged samples were found, so only the results of unaged samples were reported in this paper.

The two archaeological samples were analysed using the same method as were used to evaluate the reference materials, and the chromatograms obtained by THMPy-GC/MS are presented in Fig. 7. The main components detected in the samples of M1:1641 and M1:1681 are similar to those in the reference wax samples, which contained long-chain linear fatty acids, alcohols and hydrocarbons. However, compared with the reference materials, the amounts of hydrocarbons in the archaeological samples were significantly lower, while the amounts of fatty acids and alcohols were relatively higher. Nevertheless, the characteristics of the alkanes and alkenes were not sufficiently clear to identify the kind of wax, but the characteristics of the fatty acids were obvious. Saturated fatty acids with even numbers of carbons ranging from 14 to 34 were found in both archaeological samples, and among these species, the major compound was hexadecanoic acid (C16:0). Linear $\omega-1$ hydroxy fatty acids were also detected with 15-hydroxyhexadecanoic acid being the major species, which is consistent with the known characteristics of beeswax. By comparison with the reference samples, the fatty acid profiles of the archaeological samples (M1:1641 and M1:1681) are in accordance with beeswax (Fig. 8). 9-Octadecenoic acid, an unsaturated fatty acid characteristic of beeswax, was not found in the archaeological samples because the unsaturated carbon chain is easily broken [5].

\section{Conclusion}

The residues in bronze lamps excavated from Haihunhou Tomb were characterized using Fourier transform infrared (FT-IR) spectrometry and thermal-assisted methylation gas chromatography with mass spectrometry (THM-Py-GC/MS). The main components of the archaeological samples were identified. Through THM-Py-GC/MS analysis, the relative abundance of long-chain saturated fatty acids and the presence of $\omega$-1-hydroxy fatty acids, can be used to differentiate beeswax and Chinese wax. The remains in the two lamps could be classified as beeswax by comparison with the reference samples. So Py-GC/MS with thermal-assisted hydrolysis and methylation is an effective method for assessing the type of wax, and minimum sample preparation is required. The depletion of hydrocarbons in the remains might be attributed to preservation in a warm environment [12]. According to the morphology of the remains in the lamps, which tightly fill the interior of the lamp plates, the wax was most likely melted during burning and solidified upon cooling. This may provide additional support for the hypothesized the usage of the lamps in the past. It can be concluded that the remains were candles made of 
beeswax. The Chinese historical literature (西京杂记) reports that the vassal king of Minyue (闽越王) paid 200 candles (approximately B.C. 200), which were made of beeswax, as a tribute to the emperor of the Western Han Dynasty. Liuhe was the emperor of the Western Han for 27 days (B.C. 92-B.C. 59) before being dethroned. Although we do not know whether the beeswax residues found in the tomb of Haihunhou were the tribute from the vassal king of Minyue, it is obvious that beeswax candles were very precious at that time. In addition, the typical forms of the bronze lamps, in which beeswax residues were collected, were only used by aristocracy in Han Dynasty, indicating the precious of the bronze lamps and the wax.

\section{Acknowledgements}

The authors would like to thank the Institute of Cultural Relics and Archaeology of Jiangxi Province for providing the archaeological samples. The authors wish to thank Professor Dongbo Hu (Peking University) for his support with this study.

\section{Authors' contributions}

Professor SW and $\mathrm{HH}$ conducted the experiments and analysed the results. $J Y, L G$, and WL excavated Haihunhou Tomb, collected the archaeological samples and provided the pictures of the lamps shown in Figs. 2 and 3. All authors reviewed the submitted article. All authors read and approved the final manuscript.

\section{Funding}

Projects of the National Social Science Foundation of China (Major Program) Number: 16@ZH022.

\section{Availability of data and materials}

The datasets used and/or analysed during the current study are available from the corresponding author on reasonable request.

\section{Competing interests}

The authors declare that they have no competing interests.

\section{Author details}

${ }^{1}$ Institute of Cultural Heritage and History of Science \& Technology, University of Science and Technology Beijing, 30 Xueyuan Road, Beijing, China. ${ }^{2}$ Institute of Cultural Relics and Archaeology of Jiangxi Province, 268 Bayi Road, Nanchang, China.

Received: 12 March 2019 Accepted: 25 May 2019

Published online: 06 June 2019

\section{References}

1. Xin L. Discussion of the value and significance of archaeological excavation of the tombs of Haihunhou in the western Han Dynasty. Cult Relics Southern China. 2016;03:32-7.

2. Yang J, Xu C. Haihunhou tomb in western Han Dynasty, Nanchang. Archaeol. 2016;7:45-62

3. $\mathrm{Xu}$ C. The archaeological excavation of Haihunhou under the new concept. Cult Relics Southern China. 2016:03:38-41.

4. Pecci A, Andria FD'. Oil production in Roman times: residue analysis of the floors of an installation in Lecce (southern Italy). J Archaeol Sci. 2014;46:363-71.

5. Colombini MP, Modugno F, Ribechini E. Organic mass spectrometry in archaeology: evidence for Brassicaceae seed oil in Egyptian ceramic lamps. J Mass Spectrom. 2005;40:890-8.

6. Copley MS, Bland HA, Rose P, Horton M, Evershed RP. Gas chromatographic, mass spectrometric and stable carbon isotopic investigations of organic residues of plant oils and animal fats employed as illuminants in archaeological lamps from Egypt. Analyst. 2005;06:860-71.

7. Wu X. Research of lamps excavated in Mancheng Han tomb. Wen Wu Chun Qiu (文物春秋). 2009;1:59-72.

8. Ma S, Torres M, Li Z. Identification of beeswax excavated from the Han Period Mausoleum M1 of the King of Jiangdu, Jiangsu, China. J Archaeol Sci Rep. 2015;4:552-8.

9. Passi S, Rothschild-Boros MC, Fasella P, Nazzaro-Porro M, Whitehouse D. An application of high performance liquid chromatography to analysis of lipids in archaeological samples. J Lipid Res. 1981;22:778-84.

10. Compendium of Materia Medica (本草纲目), vol. 39. Complete library of the four branches of literature (四库全书) in Qing Dynasty. p. 1597.

11. Nanjing University of traditional Chinese medicine, Dictionary of traditional Chinese medicine; 2006. p. 1214.

12. Regert M, Colinart S, Degrand L, Decavallas O. Chemical alteration and use of beeswax through time: accelerated ageing tests and analysis of archaeological samples from various environmental contexts. Archaeometry. 2001:43:549-79.

13. Pitthard V, Griesser M, Stanek S, Bayerova T. Study of complex organic binding media systems on artworks applying GC-MS analysis: selected examples from the Kunsthistorisches Museum, Vienna. Macromol symp. 2006;238:37-45.

14. Jiménez JJ, Bernal JL, Aumente S, Del Nozal MJ, Martin MT, Bernal J. Quality assurance of commercial beeswax Part I. Gas chromatographyelectron impact ionization mass spectrometry of hydrocarbons and monoesters. J Chromatogr A. 2004;1024:147-54.

15. Kimpe K, Jacobs PA, Waelkens M. Mass spectrometric methods prove the use of beeswax and ruminant fat in late Roman cooking pots. J Chromatogr A. 2002;968:151-60.

16. Bonaduce I, Ribechini E, Modugno F, Colombini MP. Analytical approaches based on gas chromatography mass spectrometry (GC/MS) to study organic materials in artworks and archaeological objects. Top Curr Chem. 2016;374(1):6. https://doi.org/10.1007/s4106 $1-015-0007-x$

17. Evershed RP, Vagughan SJ, Dudd SN, Soles JS. Fuel for thought? Beeswax in lamps and conical cups from Late Minoan Crete. Antiquity. 1997;71:979-85.

18. Kim KJ, Eom TJ. Chemical characteristics of degraded beeswax in the waxed volume of the annals of King Sejong in the Joseon Dynasty. J Cult Herit. 2015;16:918-21.

19. Bonaduce I, Colombini MP. Characterisation of beeswax in works of art by gas chromatography-mass spectrometry and pyrolysis-gas chromatography-mass spectrometry procedures. J Chromatogr A. 2004;1028:297-306.

20. Wei S, Li Y, Ma Q, Lou S, Schreiner M. Characterization of Tang Dynasty lamp oil remains by using pyrolysis gas chromatography and mass spectrometry. J Anal Appl Pyrol. 2015;116:237-42.

21. Asperger A, Engewald W, Fabian G. Advances in the analysis of natural waxes provided by thermally assisted hydrolysis and methylation (THM) in combination with GC/MS. J Anal Appl Pyrol. 1999;52:51-63.

22. Wei S, Song G, He Y. The identification of binding agent used in late Shang Dynasty turquoise-inlayed bronze objects excavated in Anyang. J Archaeol Sci. 2015:59:211-8.

23. de Leeuw JW, Baas M. The behaviour of esters in the presence of tetramethylammonium salts at elevated temperatures; flash pyrolysis or flash chemolysis? J Anal Appl Pyrol. 1993;26:175-84.

24. Weng S. Analysis of fourier transform infrared spectroscopy. Chemical Industry Publisher; 2010.

25. Menager M, Azemard C, Vieillescazes C. Study of Egyptian mummification balms by FT-IR spectroscopy and GC-MS. Microchem J. 2014;114:32-41.

26. Luo W. Primary study of bronze artifacts in ancient Jun State, Doctoral Dissertation, University of Science and Technology of China; 2008.

27. Lu H. Study of beeswax fingerprint by gas chromatography. Master degree dissertation, Dalian Medical University; 2008.

\section{Publisher's Note}

Springer Nature remains neutral with regard to jurisdictional claims in published maps and institutional affiliations. 